\title{
Views of Irish primary school principals on implementing health-promoting school initiatives
}

\author{
A. E. Bennett ${ }^{1}$, C. Cunningham ${ }^{2}$, C. Glennon-Slattery ${ }^{2}$ and C. Johnston Molloy $^{2}$ \\ ${ }^{1}$ School of Biological Sciences, Dublin Institute of Technology, Kevin Street, Dublin 8, Ireland and ${ }^{2}$ Community Nutrition \\ and Dietetic Service, HSE Dublin Mid-Leinster, Primary Care Unit, St. Loman's Hospital Campus, Delvin Road, Mullingar, \\ Co. Westmeath, Ireland
}

Primary schools are an important setting for the promotion of healthy behaviours. However, their recognised role is to meet each pupil's educational needs, making the long-term implementation of non-obligatory school initiatives difficult ${ }^{(1)}$. The ACE (Activity Confidence Eating) Schools Programme is a non-obligatory initiative which aims to improve healthy eating, physical activity, dental health and mental health in primary schools. This study aimed to determine the views of primary school principals on how to best implement nonobligatory healthy school initiatives.

The principal of each primary school $(n 38)$ in County Longford was invited to participate in a taped semi-structured interview. Current practice and principals' views on health-promoting initiatives were assessed. Interviews were conducted in person by the researcher (AEB) and transcribed verbatim. Principal themes and sub-themes were developed.

Thirty-one principals were interviewed (82\% response rate). Twenty-two principals had implemented a healthy lunch policy in their school. Two principals had implemented policies encompassing healthy eating, physical activity, dental health and mental health. Nineteen principals acknowledged that a role of the school was to model positive lifestyle behaviours. The preferred features of an initiative were professional support ( $n 20)$, parental involvement ( $n 18)$, and curriculum integration ( $n 16)$. Lack of time ( $n 20)$, unclear programme structure $(n 12)$ and lack of parental support $(n 11)$ were the greatest barriers to participation in initiatives. The preferred method of recruiting schools to non-obligatory initiatives was face-to-face contact (n15). Timing of recruitment was crucial, with pre-Easter recruitment preferred to allow staff sufficient time to consider the initiative.

A non-obligatory school initiative most likely to be successfully implemented is one with: professional support; involvement of the school community; a foundation in the primary school curriculum; and no significant extra time commitment for teachers. This study further developed the ACE Schools Programme to better suit the needs of primary schools in the Irish midlands.

1. Foster GD, Sherman S, Borradaile KE, et al. (2009) Pediatrics 121, e794-802. 